\title{
El ojo exterior. \\ Visión y artificio a principios del siglo XVII
}

\author{
The outer eye. Vision and artifice \\ in the early seventeenth century
}

\author{
MÓNICA URIBE FLORES \\ Universidad de Guanajuato (Méjico)
}

Recibido: 5-XI-2015 Aceptado: 23-XI-2015

\begin{abstract}
RESUMEN
A principios del siglo XVII, Johannes Kepler estudió el ojo humano como instrumento óptico. Décadas más tarde, René Descartes propuso un experimento para aproximarse al ojo como si fuese un objeto separado por completo del cuerpo. Tomado como analogía de la cámara oscura, el ojo exterior ayudaría a entender la visión humana, a explicar la refracción de la luz y a modelar mejores instrumentos ópticos. Ese ojo exterior ampliaría asimismo la observación y exploración estética de la luz. El ojo objetualizado, desprendido del cuerpo humano, se convertía en materia de estudio a disposición de un observador todavía completamente corporeizado. En este extrañamiento, el ojo técnico y el ojo orgánico se observan y modelan el uno al otro.

\section{PALABRAS CLAVE}

DESCARTES, CÁMARA OSCURA, ÓPTICA MODERNA, PINTURA
\end{abstract}

\begin{abstract}
Early in the seventeenth-century Kepler studied the human eye as an optical instrument. Some decades later, Descartes proposed an experiment to approach the eye as an object, totally separated from the body. The exterior eye, assumed as an analogy of the camera obscura, would help to understand vision, to explain refraction, and to model better optical devices. That same exterior eye would broaden as well the aesthetic observation and exploration of light. The objectified eye, detached from the body, became a subject matter for an observer
\end{abstract}

(C) Contrastes. Revista Internacional de Filosofia, vol. XXI-No3 (2016), pp. 11-22. ISSN: 1136-4076

Departamento de Filosofía, Universidad de Málaga, Facultad de Filosofía y Letras Campus de Teatinos, E-29071 Málaga (España) 
still totally embodied. In this strangeness, the technical eye and the organic eye look at each other and model one another.

KEYWORDS

DESCARTES, CAMERA OBSCURA, MODERN OPTICS, PAINTING

\section{LA CÁMARA OSCURA: EL CAMINO A UN OJO EXTERIOR}

EL ILUSTRE HOLANDÉS CONSTANTIJN HUYGENS Se encontraba en Londres en 1622 cuando escribió a sus padres una carta que se ha hecho famosa por el pasaje en el que alude a las imágenes proyectadas en la cámara oscura hecha por su compatriota Cornelis Drebbel. A Huygens le pareció encontrar una belleza que no podía ser descrita: toda la pintura parecía muerta, comparada con esta nueva imagen en la que estaba la vida misma. Ahí figura, contorno y movimiento se unían como no podían hacerlo en un cuadro (Alpers 1983, 12). La cámara oscura se conocía en Europa desde tiempo atrás, y Huygens era un hombre bien informado en todos los ámbitos que pudieran llamar su atención. Alguna peculiaridad había de ofrecer la versión de Drebbel de este artilugio, de tal suerte que Huygens adquirió uno para llevarlo consigo a Holanda. Esta anécdota nos ayuda a señalar que, ya en la segunda década del siglo, la cámara oscura era algo que podía trasladarse de un país a otro y que valía la pena adquirir para observar el mundo cercano como no podía verse sin la ayuda de un instrumento. A diferencia del telescopio o del microscopio, la cámara revisitaba los objetos y lugares ordinarios y aportaba una mirada complementaria, enriquecida.

La cámara oscura ofreció, desde sus primeras y más básicas construcciones, una imagen proyectada que sin lugar a dudas correspondía a una escena natural en tiempo real. ${ }^{1}$ En Europa, sus primeros usos fueron destinados a las observaciones astronómicas y los estudios de óptica, ya en el siglo XIII; ${ }^{2}$ en el arte las referencias más tempranas que se conocen son las de los cuadernos de Leonardo da Vinci; durante el siglo XVI fue popular entre los magos e ilusionistas, además de continuar siendo un instrumento útil para los filósofos naturales. Como el nombre lo indica, en un principio se trataba de una habitación oscura, en uno de cuyos muros había un pequeño orificio que abría

1 En ocasiones propicias, la imagen proyectada puede observarse sin la necesidad de preparar un lugar cerrado, y de ello se tiene noticia desde la antigüedad.

2 A principios del siglo XI, el óptico árabe Alhazen estudió de manera sistemática el paso de la luz a través de un orificio, de modo que la cámara oscura fue un medio para estudiar fenómenos luminosos. Gracias a la imagen formada, observó que los rayos de luz no se confundían unos con otros al atravesar el orificio. 
paso a la luz, de modo que la imagen del exterior quedaba proyectada en el muro opuesto. Tal aparición era deficiente, pues estaba invertida respecto del original tanto horizontal como verticalmente, y tenía algún grado de indefinición, dependiendo de la apertura del orificio. No obstante lo anterior, el efecto resultaba fascinante, a la par que útil, por lo que de diversas maneras se buscó modificar, por un lado, las condiciones bajo las cuales se proyectaba la imagen $\mathrm{y}$, por otro, las condiciones bajo las cuales se observaba la imagen proyectada Una sencilla intervención, a guisa de ejemplo, fue la que propuso Leonardo da Vinci y que consiste en colocar un papel delgado cerca del orificio y observar la imagen desde atrás (Leonardo 1995,17$){ }^{3}$ así podría verse de cabeza pero con la orientación correcta, y el cuerpo del observador no estorbaría el paso de la luz. Ahora bien, una superficie fija, ya fuera de papel o de tela, sobre la cual se proyectara la imagen, constituía también un soporte sobre el cual dibujar, incluso si la imagen estaba invertida. Un paso decisivo en el progreso de la cámara oscura fue la introducción de un lente en la abertura por donde entraba la luz, cosa que ocurrió hacia mediados del siglo XVI. Este tipo de cámara se conoce también como cámara oscura óptica. Durante el siglo XVII la cámara oscura óptica se encontraba, al lado del microscopio y el telescopio, entre los instrumentos científicos más notables, y como tal contribuyó a pensar de un modo nuevo en el mundo visible y en la visión misma (Lefèbvre 2007, 7).

La época en que la cámara oscura tuvo un mayor auge como objeto técnico se puede situar entre 1600 y 1800 . Los modelos y tamaños fueron variando, en función de los usos y necesidades de los usuarios, así como de los recursos con los que se disponía. Desde antes del siglo XVII se habían utilizado espejos para corregir la inversión de las imágenes. Otro recurso fue el empleado por Johannes Kepler quien, como el buen astrónomo que era, optó por una combinación de dos lentes e hizo además su propio diseño de cámara, en la que la luz ya no entraba lateralmente sino desde arriba; era una suerte de tienda portátil en la que cabía una persona. Tanto el diseño de la cámara en forma de tienda como el uso de dos lentes en lugar de uno y un espejo tenían como fin la observación astronómica. Lo que aquí nos interesa es que la sustitución de espejos por lentes hacía a este tipo de cámara un instrumento más parecido a un ojo. La semejanza iba acentuándose gracias a la combinación de lentes de diferentes grosores y formas o a la posibilidad de moverlos para ajustar el foco y ver objetos que se encuentran a distancias desiguales.

Carsten Wirth afirma que una cámara oscura es particularmente especial, comparada con otros instrumentos ópticos, precisamente porque imita al ojo (Wirth 2007, 151). A principios del siglo XVII, este artificio, dotado ya de

3 Lo que Leonardo describe es en efecto la cámara oscura, pero como experimento para entender cómo es que los objetos transmiten sus imágenes al ojo. 
lentes, fue abiertamente aceptado y tratado como analogía del ojo, que a partir de este momento sería un órgano objetualizable.

\section{LA ÓPTICA MODERNA: KEPLER Y EL DESPRENDIMIENTO DEL OJO}

Cuando Johannes Kepler emprendió sus estudios sobre la parte óptica de la astronomía, al despuntar el siglo XVII, introdujo el estudio del ojo como uno de los temas propios de esta ciencia. El ojo fue presentado en el prefacio de $\mathrm{Ad}$ Vitellionem Paralipomena (1604) como un instrumento óptico similar a una cámara oscura. La comparación no era nueva pero es interesante observar que fue Kepler quien pudo ofrecer una explicación que la tornara operante. Bien es sabido que ya Da Vinci se había visto tentado por esta analogía, a la que no sucumbió por no poder resolver el problema de que la imagen en la cámara oscura aparece invertida, y no es así como vemos. ${ }^{4}$ La citada obra de Kepler surgió a partir de la identificación de una anomalía durante la observación de un eclipse: el diámetro de la luna parecía disminuir, lo cual no podía ser atribuible más que a la falibilidad de la observación. En la propia estructura y funcionamiento del ojo había que buscar, pensaba Kepler, el origen del problema de las inexactitudes en la observación y medición astronómicas. Fue así como la óptica, de ser fundamentalmente el estudio perspectivista de la visión, se tornó en el estudio físico de la luz. ${ }^{5}$

El quinto capítulo del tratado está dedicado a la visión. Kepler inicia con un apartado sobre la descripción del ojo, basándose en los conocimientos de anatomía expuestos en las obras de los profesores de medicina Felix Plater y Johannes Jessenius, quienes enseñaban en Basel y Praga, respectivamente. En su De partium corporis humani structura et usu (1583 y 1603), Plater hace ya una explícita referencia al ojo como cámara oscura, sin llegar a desarrollar la idea; de modo que es Kepler quien tiene la ocasión de tratar la analogía con amplitud. ${ }^{6}$ Antes de tratar al ojo como instrumento óptico, cuando Kepler todavía lo sitúa en un cuerpo humano, hace varias consideraciones interesantes,

4 Leonardo pensaba que la imagen de los objetos se invierte dos veces en el ojo: la primera de ellas en la pupila y la segunda en el cristalino. «Ninguna imagen, incluso la del más pequeño objeto, entra en el ojo sin ser vuelta al revés, pero cuando penetra en el cristalino es nuevamente cambiada en sentido contrario y así la imagen vuelve a la misma posición dentro del ojo como la del objeto que está fuera.» (Leonardo 1995, 17).

5 Cabe mencionar que en el siglo XVII hubo una separación importante entre dos conceptos que antes se usaban indistintamente: lux y lumen; el primero se destinó al sentido metafísico y el segundo al sentido físico. La luz (lumen) tuvo así su propio término para constituirse como objeto de estudio de la óptica moderna.

6 Estas ideas servirían unas décadas más tarde para el desarrollo del modelo ocular del médico belga Vopiscus Fortunatus Plempius (1601-1671). Vid. Vanagt 2012. 
al hilo de las explicaciones de los médicos referidos. Para empezar, establece la importancia y utilidad de una visión binocular y de la ubicación de los ojos en la parte más elevada del cuerpo; hasta aquí, el humano tiene esto en común con muchos animales. Pero los humanos somos seres sociales y políticos que cambiamos nuestra propia historia; los ojos, situados en la cara, son necesarios para socializar con nuestros congéneres. Además, dado que somos seres dignos que no pastamos ni nos arrastramos por el suelo, necesitamos tener la cara dirigida a las cosas distantes, hacia el horizonte o hacia el cielo. Como ya Galeno había sostenido, la cabeza está elevada en el cuerpo y así los ojos están cerca del cerebro. Kepler reconocerá que los ojos se comunican con el cerebro pero no se detendrá en estudiar qué pasa más allá de la formación de una imagen retiniana, por considerar que esa tarea corresponde a los filósofos. En efecto, cuando René Descartes retome los estudios de óptica de Kepler, algunas décadas más tarde, les dará un sesgo epistemológico, al establecer la relación entre la imagen retiniana y la representación mental, como más adelante veremos.

Pero demos un pequeño paso atrás en esta historia. La idea de que el ojo recibe imágenes de los objetos que ve en el exterior fue dominante en el pensamiento griego. En el mundo árabe del siglo XI, el Libro de óptica de Alhazen propuso que el ojo no es un receptor sino un formador de imágenes, de modo tal que un objeto visible puede entenderse como un conjunto de puntos, cada uno de los cuales envía un rayo de luz al ojo (Crombie 1996, 304). Los ópticos europeos del siglo XIII, principalmente Witelo, Roger Bacon y John Peckham, recibieron las ideas de Alhazen y las heredaron a la modernidad. Hacia principios del siglo XVII se sabía que el ojo formaba imágenes a partir de la luz que entra través de la pupila. Felix Plater fue el primero en identificar que la parte sensible del ojo en la que estas imágenes se proyectaban era la retina. Pero fue Kepler, como estudioso de la naturaleza de luz, quien consolidó la teoría de la imagen retiniana.

En términos básicos, lo que esta teoría sostiene es que « [s]i los rayos luminosos son emitidos en todas direcciones desde cada punto en el campo visual, entonces es necesario seguir estos rayos hacia el ojo y a través de él, y establecer una correspondencia uno a uno entre los puntos que envían la radiación y los puntos estimulados dentro del ojo» (Lindberg 1976, 193). Tal correspondencia sugirió a Kepler que la imagen retiniana era como una pintura, y que los rayos de luz eran como las pinceladas que la formaban. El sentido de esta analogía es, como puede notarse, restringido, pues la noción de pictura que el astrónomo tiene en mente se refiere estrictamente al ordenamiento físico de haces de luz que entran a través de la pupila (equivalente al orificio de la cámara oscura), se refractan en los humores (que operan como lentes) y forman una imagen doblemente invertida en la retina (que funciona como la pantalla en la que se proyecta la escena exterior en la cámara oscura). La analogía 
entre imagen retiniana y pintura ha de entenderse como una suerte de pintura natural, no de pintura artística. Aquí la diferencia es crucial, pues en un caso se trata de imágenes formadas y en el otro de imágenes creadas. Kepler no trata la pintura retiniana como si fuera una representación; enseguida veremos que tampoco Descartes lo hará, pues representar requiere la intervención del alma, y formar una imagen en la retina es una operación meramente óptica. Para estudiar la visión y, a partir de ahí, las condiciones de observación de fenómenos astronómicos, Kepler ha separado teóricamente al ojo del resto del cuerpo y también lo ha disociado de la mente; el instrumento óptico que se propone estudiar es, sencillamente, un objeto.

\section{DESCARTES: UN HOMBRE MIRA UN OJO}

En un famoso grabado que aparece en el Discurso V de la Dióptrica (1637), de René Descartes, vemos a un hombre mirando el reverso de una imagen retiniana. El hombre se encuentra dentro de un lugar oscuro; su cabeza está inclinada hacia arriba, muy cerca de ese ojo aislado, a través de cuya pupila entran los rayos de luz exterior. Ese glóbulo ocular es tan grande, que la cabeza del hombrecillo cabría sobradamente dentro de él. El ojo observado pareciera ser un astro o un mundo en sí mismo.

En la línea trazada por Kepler, Descartes publicó la Dióptrica, obra dedicada al estudio de la luz, cuya pretendida finalidad era orientar a los fabricantes de lentes destinados a instrumentos de observación. Descartes había tenido interés por la refracción desde mediados de la década anterior. La Dióptrica apareció junto con sus otros trabajos científicos, la Geometría y los Meteoros, precedidos por el Discurso del Método. Años antes de su publicación, Descartes tenía en mente el proyecto de una nueva filosofía, a la que estos trabajos habían de corresponder. Como es sabido, la condena a Galileo Galilei en 1633 tuvo un fuerte impacto en el filósofo francés, al punto que llegó a pensar que jamás publicaría sus obras. Sin embargo, continuó trabajando, animado por algunos amigos como Constantijn Huygens, Jacob Golius, Henricus Reneri y Marin Mersenne. Hay que tener en cuenta que, a pesar de que para la filosofía el Discurso es a todas luces un texto canónico, la obra que vertebró la publicación fue precisamente el ensayo sobre la refracción de la luz. ${ }^{7}$ En realidad, la Dióptrica es una obra temprana de Descartes, aunque su decisión de publicarla tuviera que esperar hasta el otoño de 1635. La primera mención a este trabajo aparece en una carta escrita a Mersenne en noviembre de 1630, pero hay indicios de que estaba muy avanzado o casi terminado cuando el filósofo llegó a Holanda, en 1628. Lo cierto es que Golius, profesor de árabe y matemáticas en

7 Sobre la relación entre estos textos, el lector puede consultar Ariew, Des Chenne, et. al. 2010. Ahí encontrará una referencia sencilla pero precisa y confiable. 
Leiden, recibió en 1632 una copia de la Dióptrica, de la que habló a Constantijn Huygens, pues ambos eran grandes entusiastas de la óptica.

Al igual que Kepler, Descartes dedicó algunas secciones a la exposición de los mecanismos visuales $\mathrm{y}$, a diferencia del astrónomo alemán, derivó de ellos implicaciones epistemológicas. Para ello tuvo que mantener la formulación del ojo como instrumento óptico, al cual posteriormente conectaría con el cerebro a través de los nervios; una vez asociada la visión al cerebro, ésta quedaría vinculada con el alma, la sustancia pensante. Sólo a partir de ahí podría hablarse de representación, es decir, del tipo de idea ala que Descartes llama adventicia, y que distingue tanto de la idea innata como de la ficticia. El alma recibe impresiones a través de los órganos de los sentidos pero no son los órganos los que sienten sino el alma. Sentir es una función exclusiva de la res cogitans.

Descartes inicia el quinto discurso de la Dióptrica con la afirmación de que los objetos que vemos imprimen imágenes perfectas en el fondo del ojo, aun cuando éstas no se asemejen a los objetos que percibimos. Hay quienes han explicado de manera ingeniosa la formación de estas imágenes, escribe el filósofo, comparándolas con las que aparecen en una recámara casi totalmente a oscuras. Como es de esperarse, lo que sigue es la descripción de una cámara que, en este caso, cuenta con un lente y una tela estirada que sirve como pantalla. Los que usan esta comparación, continúa Descartes, toman la habitación como el ojo, el orificio como la pupila, el lente como las partes del ojo que causan la refracción de la luz y, por último, la pantalla como la membrana interior -la retina-.

En apoyo a la analogía de la cámara oscura, Descartes sugiere separar ojo y cuerpo, con el fin de observar cómo se comporta el instrumento óptico. Para ello propone el siguiente experimento: tomar el ojo de un hombre o bien de algún animal grande, por ejemplo un buey, que recién haya muerto; desprender el ojo de las membranas posteriores con mucho cuidado, de tal manera que una gran parte del humor vítreo quede expuesto; depositarlo en un material blanco muy delgado, capaz de dejar pasar la luz del sol, por ejemplo, un trozo de papel o una cáscara de huevo; colocar el ojo en el hueco de una ventana hecha para ese fin. La parte anterior, en la que se encuentra la pupila, debe quedar orientada hacia donde se ubican los objetos iluminados, mientras que la parte posterior, soportada por el cuerpo blanco (la cáscara de huevo, digamos), debe quedar dentro de una cámara (Descartes 1996, 115). Este ojo desprendido, exteriorizado totalmente, ¿es un ojo extraño? El experimento no ha terminado; el observador ha de situarse dentro de la cámara, cerrada por completo a la luz exterior. El observador mira entonces hacia el ojo y lo que tiene es el reverso de la imagen formada por los rayos que entraron a través de la pupila. Así es como puede ver, dice Descartes, quizá con admiración y placer, una pintura de los objetos 
exteriores. Es decir, algo equivalente a la imagen retiniana, resultado final de la travesía lumínica; he aquí la pictura, como la había llamado Kepler.

Después de leer el pasaje en el que Descartes nos lleva a imaginar que sacamos el ojo de un animal que apenas hace poco estaba vivo - un animal que bien podría ser un congénere- $\mathrm{y}$ lo ponemos en posición de recibir, refractar y proyectar rayos luminosos, el que se dibujen objetos ya no causa sorpresa alguna; en cambio, lo que provoca cierta perplejidad es la literalidad con la que el ojo, compuesto de partes frágiles a las que hay que manejar con delicadeza, es una cámara oscura. El experimento propone una transformación: un instrumento puede ser construido a partir de un órgano; pero también nos muestra la circularidad con la que el objeto técnico y el objeto orgánico se modelan el uno al otro. La cámara ayuda a entender el ojo. El entendimiento del ojo ayuda a perfeccionar instrumentos ópticos; no olvidemos que la observación asistida, particularmente la astronómica, está en el origen de la Dióptrica.

Ahora bien, así como Kepler consideró la importancia de contar con dos ojos, Descartes no subestima el hecho de que nuestra visión es binocular. El alma unifica las dos imágenes que reciben los ojos. Desde luego que para estudiar el mecanismo de la formación de imágenes no es necesario acudir a los dos ojos y, como hemos visto, mucho menos al alma.

El ojo exterior es un órgano desmembrado al que podemos mirar desde atrás como a un artefacto. Ya hemos visto que es un instrumento óptico separable del cuerpo; lo que sucede al interior de este aparato de observación es a su vez observable y, lo que es más importante, es objeto de investigación para el filósofo moderno. El ojo cartesiano pertenece al mundo material, como el resto de su cuerpo. Así que aun antes de haberse desprendido del cuerpo es ya una sustancia distinta del alma que la piensa. El ojo exterior concebido para ser estudiado es, a diferencia del ojo corporal, un artificio para entender el comportamiento de la luz que pasa por los medios traslúcidos del ojo orgánico y que forma las imágenes inmateriales a partir de las cuales tenemos ideas acerca del mundo visible. Pero al igual que el ojo corporal y que todos los demás instrumentos ópticos, el ojo exterior es insensible. Puesto de manera inversa, al igual que el ojo exterior y que cualquier instrumento óptico, el ojo corporal es insensible, es una res extensa, cuya esencia es tener tres dimensiones y estar en movimiento. Hasta aquí, sea exterior u orgánico, humano o animal, el ojo cartesiano es una cosa. Y sin embargo, el ojo exterior se distingue del ojo orgánico, y el animal se distingue del humano por algo fundamental; el ojo humano o, habrá ahora que decir «los ojos humanos» en un cuerpo vivo, sin dejar de ser materia, están unidos al alma. Esto tendrá, en el concierto de la filosofía cartesiana -y no ya solamente de la teoría de la visión-, al menos dos consecuencias importantes; la primera es de naturaleza epistémica: el alma puede ver, tener ideas adventicias relacionadas con las cualidades visibles; la segunda es de índole afectiva y se 
traduce en que el alma puede, si se me permite la expresión, ser vista. A esta consecuencia se asoma Descartes, principalmente, en Las Pasiones del Alma (1649).Esta segunda deriva desborda el tema del presente ensayo; sin embargo, no está de más recordar que la filosofía cartesiana tiene diversos pliegues. En el tratado dedicado a las pasiones, Descartes afirma que a través del cuerpo se manifiesta lo que sucede en el alma; particularmente en el rostro y, de manera notable, en los ojos podemos advertir si una persona siente alegría, enojo, amor o cualquier otra afección. «No hay pasión alguna que no sea revelada por algún gesto de los ojos» (Descartes 2002, 145). El cuerpo es el medio expresivo del alma, de manera natural e involuntaria. Así como el mundo es sentido por el alma, el alma tiene sus modos no discursivos de mostrarse.

Pero volvamos ahora al ensayo sobre la refracción, y con él a la consecuencia epistémica de que los ojos humanos actúen en unión con el alma. La Dióptrica abre con una afirmación que podría deslumbrar a quienes desconocen o desestiman el lugar que el conocimiento sensible tiene en el pensamiento cartesiano. Descartes inicia el primer discurso, dedicado a la luz, diciendo que « [t] oda la conducción de nuestra vida depende de nuestros sentidos, entre los cuales el de la vista es el más universal y el más noble» (Descartes 2002, 81). Fuera de contexto, podría pensarse que Descartes se refiere al ámbito práctico y que la frase no rebasa el sentido común. Pero recordemos que la obra que estudia la luz pretende aportar conocimiento físico, orientado a mejorar la construcción de instrumentos de observación que, a su vez, contribuirán al conocimiento del mundo natural. Como bien en sabido, este conocimiento para Descartes no puede alcanzar la certeza metafísica; no obstante, por limitado o falible que sea, no es conocimiento despreciable. Ahora bien, si el conocimiento del mundo natural no se basa en las prácticas ni en la experiencia ordinaria sino en la filosofía natural, cuyo fundamento es la matemática, tenemos un ámbito epistémico de un rango superior, más confiable.

La observación asistida por instrumentos hechos ex profeso es promovida por el propio Descartes, siempre y cuando se fabriquen sobre la sólida base de la explicación físico-matemática. El ojo orgánico, mantenido en el cuerpo vivo, es la vía de enlace entre el mundo visible y alma; en esta condición, es un órgano que inevitablemente aporta información engañosa. Pero el ojo orgánico, promovido a ojo exterior, es el paso al perfeccionamiento de la observación.

\section{UN GUIÑO FINAL: JOHANNES VERMEER Y LOS ARTIFICIOS DEL OJO EXTERIOR}

Un discreto universo de cosas, personas anónimas y hábitos, todos ellos aparentemente irrelevantes, reposan en un lienzo. Es el cuadro de escenas cotidianas, género cultivado y perfeccionado en Holanda en el siglo XVII. Vemos una habitación doméstica, iluminada por la luz natural que entra por las ventanas, algunas veces por una puerta. La condición de familiaridad de 
cuanto aparece en el cuadro ha dado al pintor una extraordinaria ocasión para ver y recrear el mundo inmediato, ese que puede ser tocado, movido, recolocado y que, además, es susceptible de ser explorado a través de lentes acomodados estratégicamente en una cámara oscura óptica. A pesar de que es imposible demostrar que la cámara fuera utilizada por los pintores holandeses del siglo que nos ocupa, existe una fuerte sospecha de que algunos lo hicieron. Esta suerte de ojo instrumental ofrecía al pintor condiciones para ver e integrar una gama de efectos imposibles de observar sin un aparato óptico adicional. ¿Qué consecuencias tendría este nuevo ojo para la mirada del artista?

La pintura de escenas cotidianas, también conocida como pintura de género, tuvo entre sus más notables exponentes a Johannes Vermeer de Delft, quien ha recibido una particular atención en lo que respecta al posible uso del referido artefacto, debido a los peculiares efectos ópticos que pueden notarse en muchas de sus pinturas de interiores domésticos. Philip Steadman sostiene que la cámara oscura abrió a Vermeer un mundo de fenómenos ópticos que apenas estaba siendo descubierto. En una época en la que «producir imágenes pictóricas con lentes era a la vez original y prestigioso», la cámara permitía indagar cómo estos fenómenos podían quedar registrados en un cuadro (Steadman 2001, 1). El color y los contrastes de luz se veían con mayor intensidad; los contornos de algunos objetos, particularmente los metálicos, se veían borrosos.

Recordemos la analogía entre la imagen retiniana y la pintura; por discutible y limitada que pueda ser en términos estéticos la comparación, hay una característica común resaltada por los filósofos naturales: la bidimensionalidad. Mientras que desde un punto de vista epistemológico ésta sería una limitación, algo que hace engañosas a las imágenes, dado que la realidad es tridimensional, para los artistas la inevitable bidimensionalidad del lienzo ofreció un fascinante reto: crear imágenes visualmente convincentes como si hubiera un plano de profundidad. La cámara oscura no sería el único ni el más importante artificio para responder al reto, pero tuvo su lugar en él. Laura Snyder señala que la cámara hacía una valiosa aportación a los pintores, al proporcionar una imagen bidimensional a partir de una escena tridimensional; es decir, producía una representación plana del espacio, equiparable a la que los pintores buscaban crear por medio de la perspectiva y el uso del color, la sombra y la luz (Snyder 2015, 147).

De acuerdo con Martin Kemp, el uso de la cámara oscura en el arte podrá entenderse cabalmente cuando se abandone el prejuicio de que se trata de un recurso tramposo para evadir las dificultades a las que se enfrenta el verdadero artista. Sin duda, la cámara puede ayudar en el dibujo y la perspectiva, pero lo que aquí nos ocupa es la aplicación que tiene como instrumento de observación, ya no en un sentido científico sino estético. Este ojo exterior modificado permitió ver, explorar y modular la luz, sus valores y sus efectos. 
En el caso particular de Vermeer, Wayne Franits sugiere que pudo no haber utilizado la cámara obscura para pintar pero sí para observar, y que los efectos producidos por este aparato estimularon sus intereses estéticos. Según Franits, en Oficial y joven que ríe aparecen las primeras evidencias del interés de Vermeer por los instrumentos ópticos; por un lado, en este cuadro hay una desproporción considerable entre el tamaño del soldado en el primer plano y el de la joven, quien no se encuentra lo suficientemente lejos de él como para aparecer tan disminuida; por otro lado, en esta pintura podemos notar objetos borrosos, como si estuvieran fuera de foco (Franits 2001, 14). Este segundo efecto es uno de los que se pueden observar gracias a una cámara oscura con lente.

La imagen, gracias al uso de lentes, a la distancia focal, al control de la luz en un espacio reducido, se torna más definida, más rica en efectos ópticos. El pintor tenía entonces una ayuda no para evitarse la dificultad de lidiar con el dibujo sino para ampliar las posibilidades del juego de luz, sombra y armonía del color, gracias a la observación asistida. No es difícil imaginar a Vermeer cambiando las condiciones de luz; observando diferentes efectos ópticos sobre las superficies; haciendo coincidir en el lienzo lo que podría verse a lo largo de horas, acaso días, en que el ojo exterior captaba matices y variaciones ahora disponibles para la mirada inventiva del pintor.

\section{REFERENCIAS BIBLIOGRÁFICAS}

ALPERS, S. 1983: The Art of Describing. Chicago: The University of Chicago Press. ARIEW, R., DES CHENE, D., et. al. 2010: The A to Z of Descartes and Cartesian Philosophy. Lanham: The Scarecrow Press.

CROMBIE, A. 1996: «Expectation, Modelling and Assent in the History of Optics», en Crombie. Science, Art and Nature in Medieval and Modern Thought. Londres: The Hambledon Press, pp. 301-355.

Descartes, R. 1996: «La Dioptrique», en Ch. Adam y P. Tannery (eds.), Oeuvres de

Descartes. París: J. Vrin, vol. VI, 81-228.

DESCARTES, R. 2002: Meditaciones metafísicas. Las pasiones del alma. Barcelona: Folio. FRANITS, W. (ed.) 2001: The Cambridge Companion to Vermeer. Cambridge: Cambridge University Press.

KEMP, M. 2000: La ciencia del arte. Madrid: Akal.

KePLeR, J. 2000: Optics. Santa Fe: Green Lion Press.

LEFÈBVRE, W. 2007: «The Optical Camera Obscura. I A Short Exposition» en W. Lefèbvre (ed.), Inside the Camera Oscura. Berlín: The Max Planck Institute for 
the History of Science, pp. 5-11.

LEONARDO DA VINCI. 1995: Cuadernos de notas. Barcelona: Planeta-De Agostini.

LINDBERG, D. 1976: Theories of vision from Al-Kindi to Kepler. Chicago: The University of Chicago Press.

SNYDER, L. 2015: Eye of the Beholder. Nueva York: W.W. Norton \& Company.

STEADMAND, P. 2001: Vermeer's Camera. Oxford: Oxford University Press.

VANAGT, K. 2012: «Vision and the Camera Obscura. V.F. Plempius' Ophthalmographia», en M. Horstmanshoff, H. King y C. Zittel (eds.), Blood, Sweat and Tears. The Changing Concepts of Physiology from Antiquity into Early Modern Europe. Leiden: Brill, pp. 569-593.

WIRTH, C. 2007: «The Camera Obscura as a Model of a New Concept of Mimesis in Seventeenth-Century Painting», en W. Lefèbvre (ed.), Inside the Camera Oscura. Berlín: The Max Planck Institute for the History of Science, pp. 149-193.

Mónica Uribe Flores es Profesora a tiempo completo en el Dpto. de Filosofía de la Universidad de Guanajuato (Méjico). 